\title{
Radiological study of the sacroiliac joints in vertebral ankylosing hyperostosis
}

\author{
M. BRIGODE, ${ }^{1}$ R. J. FRANCOIS, ${ }^{2}$ AND M. A. DORY ${ }^{3}$ \\ From the Departments of ${ }^{12}$ Rheumatology and Rehabilitation and ${ }^{3}$ Radiology, Clinique Saint-Pierre, Ottignies, \\ Belgium, and the Department of ${ }^{2}$ Rheumatology, Military Hospital, Brussels, Belgium
}

SUMmARY A radiological study of the sacroiliac joints was undertaken in 54 patients (32 males, 22 females) with vertebral ankylosing hyperostosis (VAH) and in 46 control patients ( 24 males, 22 females) matched for age and sex. The ages ranged from 38 to 90 years. The radiographs were taken in anteroposterior, oblique, and craniocaudal projections. The films were read for cranial, ventral, and caudal capsular ossifications, for ventral and caudal osteophytes, and for bone sclerosis. Cranial and/or ventral capsular ossifications were found in $28(87 \cdot 5 \%)$ males with VAH and in $4(16.6 \%)$ control males $(\mathrm{p}<0.0005)$, but only in 2 females with VAH and no control female. Sacroiliac capsular ossifications in males with VAH are frequent from the onset, but complete bridging of the joint is not reached before the sixth decade. Women, either VAH or control, have more sacroiliac osteophytes than men. There were 11 out of 22 control women with osteophytes versus 4 out of 24 men $(p<0 \cdot 025)$. The incidence of osteophytes does not seem to increase with age after 50 years. Our findings support the idea of VAH being a distinct entity and not a major form of osteophytosis.

In their original description of vertebral ankylosing hyperostosis (VAH) Forestier and Rotes-Querol ${ }^{1}$ stressed the normal appearance of the sacroiliac (SI) joints, considering it as a diagnostic criterion, especially for the differential diagnosis from ankylosing spondylitis. Dihlmann and Freund ${ }^{2}$ described SI capsular ossifications in VAH. However, earlier reports ${ }^{3-5}$ mentioned the fibrous, cartilaginous, and osseous ankylosis of aging SI joints. The question then arises whether the extra-articular bony fusion between sacrum and iliac bone seen in VAH is not merely an aging phenomenon.

We therefore decided to study the radiological aspects of the SI joints in VAH patients and in control patients, matched for age and sex.

\section{Materials and methods}

To avoid conditions with inflammatory SI changes or paravertebral ossifications which might be confused with VAH, no patients with rheumatoid arthritis, ankylosing spondylitis, Reiter's or Crohn's disease,

Accepted for publication 9 June 1981

Correspondence to Dr M. Brigode, Clinique Saint-Pierre, 1340 Ottignies, Belgium.

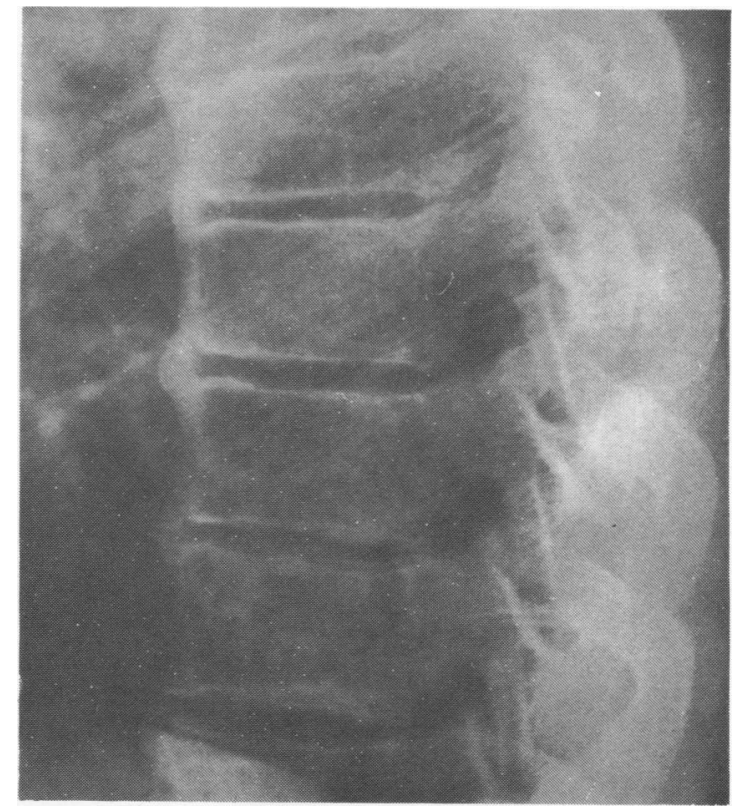

Fig. 1 Typical radiological appearance in VAH: thick paravertebral bone layer and complete intervertebral bridges. 
Table 1 Mean number of vertebral bodies coated by a paravertebral bone layer in the VAH patients, per decade

\begin{tabular}{lll}
\hline Age & Men & Women \\
\hline $31-40$ & $1 \cdot 0$ & \\
$41-50$ & $1 \cdot 3$ & \\
$51-60$ & $3 \cdot 3$ & $3 \cdot 3$ \\
$61-70$ & $3 \cdot 2$ & $3 \cdot 7$ \\
$71-80$ & $4 \cdot 3$ & $2 \cdot 6$ \\
$81-90$ & $5 \cdot 0$ & $6 \cdot 5$ \\
\hline
\end{tabular}

ulcerative colitis, psoriasis, known chondrocalcinosis, moderate to severe scoliosis, or vertebral collapse were considered for this study. To be included in the VAH series patients had to present at least 2 complete intervertebral bridges and a typical bone cast along one vertebral body (Fig. 1). Most patients had several vertebral bodies coated with a paravertebral bone layer, which extended progressively with age (Table 1 ). In one patient with cervical myelopathy the symptoms could be definitely ascribed to his VAH. In a few with spinal or hip

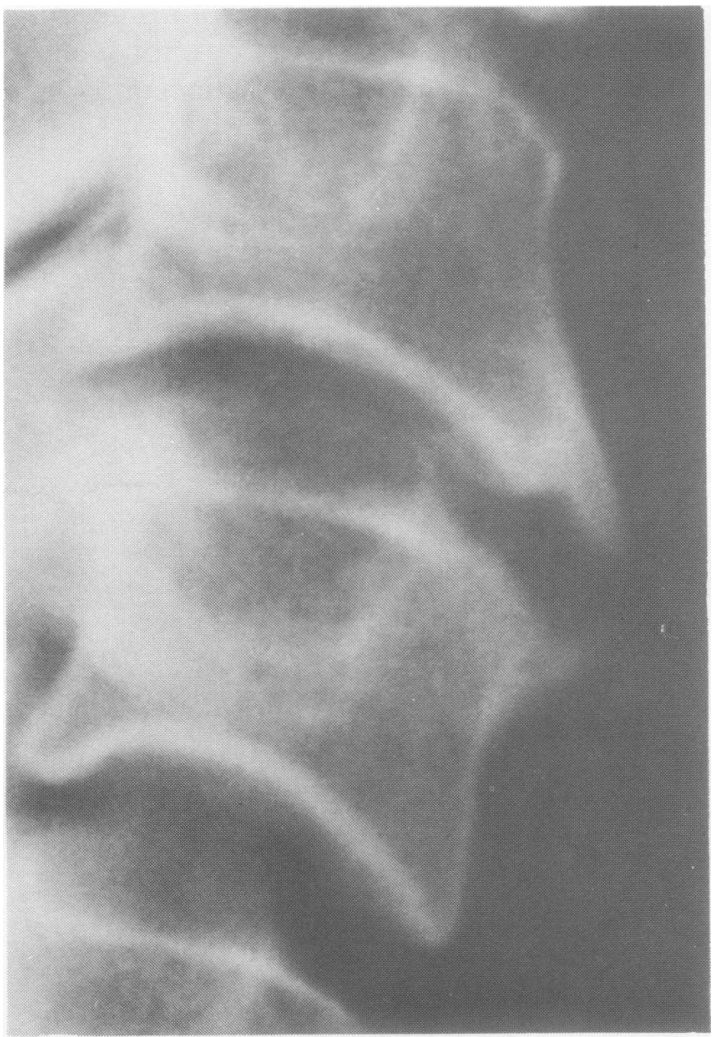

Fig. 2 Broad-based osteophyte at the anteroinferior corner of a cervical vertebral body. Patients with such lesions were excluded from the control group.

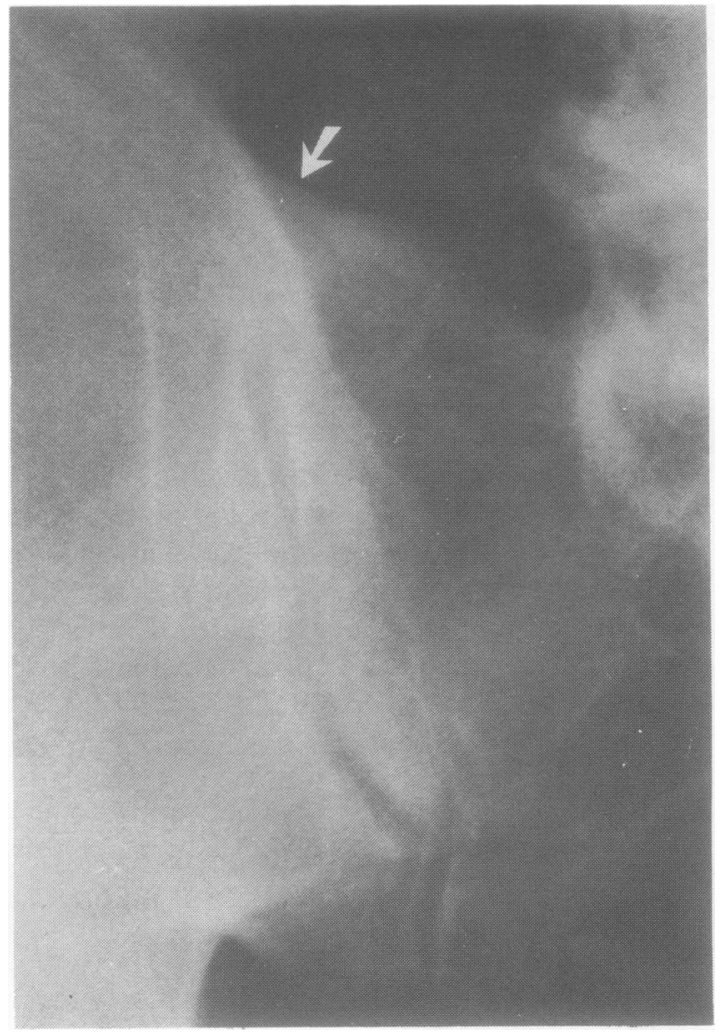

Fig. 3 51-year-old VAH male; anteroposterior view of the right sacroiliac joint disclosing complete cranial bridging (arrow).

changes such a relationship was questionable. Most were referred to us for degenerative conditions such as osteoarthrosis of knee, hip, or spine, painful shoulder, lumbosciatica, or multiple complaints.

We selected as controls patients with diffuse neck and back complaints requiring $x$-ray examination of the whole spine and not showing the slightest

Table 2 Age and sex distribution of $V A H$ and control patients

\begin{tabular}{|c|c|c|c|c|}
\hline \multirow[t]{2}{*}{ Age } & \multicolumn{2}{|c|}{$V A H$ group } & \multicolumn{2}{|c|}{ Control group } \\
\hline & $M$ & $F$ & $M$ & $F$ \\
\hline $31-40$ & 1 & 0 & 0 & 0 \\
\hline $41-50$ & 3 & 0 & 4 & 0 \\
\hline $51-60$ & 6 & 3 & 10 & 4 \\
\hline $61-70$ & 13 & 7 & 6 & 10 \\
\hline $71-80$ & 6 & 10 & 2 & 6 \\
\hline $81-90$ & 3 & 2 & 2 & 2 \\
\hline Total & 32 & 22 & 24 & 22 \\
\hline Grand totals & \multirow{2}{*}{\multicolumn{2}{|c|}{$\begin{array}{l}54 \\
66 \cdot 76\end{array}$}} & \multirow{2}{*}{\multicolumn{2}{|c|}{$\begin{array}{l}46 \\
64 \cdot 22\end{array}$}} \\
\hline Mean age & & & & \\
\hline
\end{tabular}

No statistically significant difference in this distribution (chi-square) nor in the mean age (Student's $t$ test). 
Table 3 Number of patients presenting sacroiliac (SI) changes

\begin{tabular}{|c|c|c|c|c|c|c|}
\hline \multirow[t]{2}{*}{ SI changes } & \multicolumn{3}{|l|}{ Men } & \multicolumn{3}{|l|}{ Women } \\
\hline & $\begin{array}{l}V A H \\
n=32\end{array}$ & $\begin{array}{l}\text { control } \\
n=24\end{array}$ & $p$ & $\begin{array}{l}V A H \\
n=22\end{array}$ & $\begin{array}{l}\text { control } \\
n=22\end{array}$ & $p$ \\
\hline \multicolumn{7}{|l|}{ Capsular ossification } \\
\hline $\begin{array}{l}\text { Cranial } \\
\text { Ventral }\end{array}$ & 18 & 2 & $<0.001$ & 1 & $\mathbf{0}$ & NS \\
\hline complete bridge & 17 & 1 & $<0.0005$ & 0 & 0 & NS \\
\hline incomplete bridge & 10 & 1 & $<0.05$ & 2 & 0 & NS \\
\hline Cranial and/or ventral & 28 & 4 & $<0.0005$ & 2 & 0 & NS \\
\hline Caudal & 6 & 2 & NS & 1 & 1 & NS \\
\hline \multicolumn{7}{|l|}{ Osteophytes } \\
\hline Caudal & 0 & 3 & NS & 3 & 5 & NS \\
\hline Ventral & 3 & 3 & NS & 5 & 9 & NS \\
\hline Caudal and/or ventral & 3 & $4^{*}$ & NS & 8 & $11^{*}$ & NS \\
\hline Bone sclerosis & 7 & 4 & NS & 5 & 2 & NS \\
\hline
\end{tabular}

NS = not significant. ${ }^{*}$ Difference between male and female control patients is significant $(p<0.025)$.

trend to VAH, such as, for example, a single broadbased osteophyte (Fig. 2). It is important to have radiographs of the 3 spinal segments, since VAH can start in any area. Two patients were transferred from the control to the VAH group after completion of their radiological examination. The inclusion of a

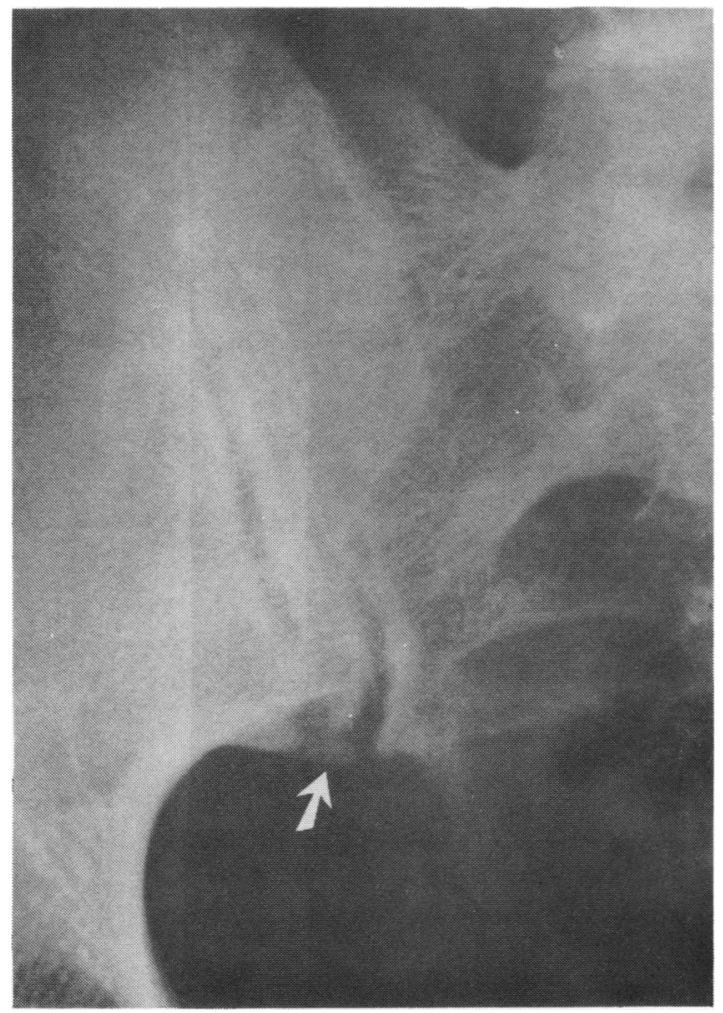

Fig. 4 Anteroposterior view of the right sacroiliac joint of a $V A H$ male; incomplete caudal bridge (arrow). patient in the control group was decided on the spinal films without taking the SI pictures into account. At least 2 of the 3 authors had to agree on the decision.

As regards matching for age and sex, both series were built up simultaneously and on a consecutive basis. After a certain time it became apparent that too many younger control patients (under 50 years of age) and older VAH patients (over 65 years of age) were included. Recruiting in those classes was stopped. Finally $54 \mathrm{VAH}$ and 46 control patients were entered, with comparable age and sex distribution (Table 2).

Four radiographic views were taken from each SI joints: anteroposterior, oblique axial and antiaxial, and craniocaudal axial according to Dory and François. $^{6}$ The films were read by 3 observers-2 rheumatologists (M.B. and R.J.F.) and one radiologist (M.D.) without knowledge of the diagnosis. They were coded for the presence of capsular ossification (Figs 3-7), osteophytes (Fig. 8, 9) and bone sclerosis (Fig. 10). Capsular ossifications were described as complete bridges (Figs 3, 5, 6) or incomplete ones (Fig. 4, 7) and, according to their location, as cranial (Fig. 3, 6A), caudal (Fig. 4, 6A), or ventral (Fig. 5, $6 \mathrm{~B}, 7)$. Likewise the osteophytes were tabulated as caudal (Fig. 8) or ventral (Fig. 9).

Table 4 Number of female control patients with caudal or ventral osteophytes, according to age

\begin{tabular}{lllll}
\hline Age & $\begin{array}{l}\text { No. of } \\
\text { patients }\end{array}$ & \multicolumn{3}{l}{ No. of patients with osteophytes } \\
\cline { 3 - 5 } & & Caudal & Ventral & $\begin{array}{l}\text { Caudal and/or } \\
\text { ventral }\end{array}$ \\
\hline $51-60$ & 4 & 1 & 2 & 2 \\
$61-70$ & 10 & 2 & 4 & 4 \\
$71-80$ & 6 & 2 & 2 & 4 \\
$81-90$ & 2 & 0 & 1 & 1 \\
Total & 22 & 5 & 9 & 11 \\
\hline
\end{tabular}




\section{Results}

The distribution of capsular ossifications, osteophytes, and bone sclerosis in both groups is shown in Table 3.
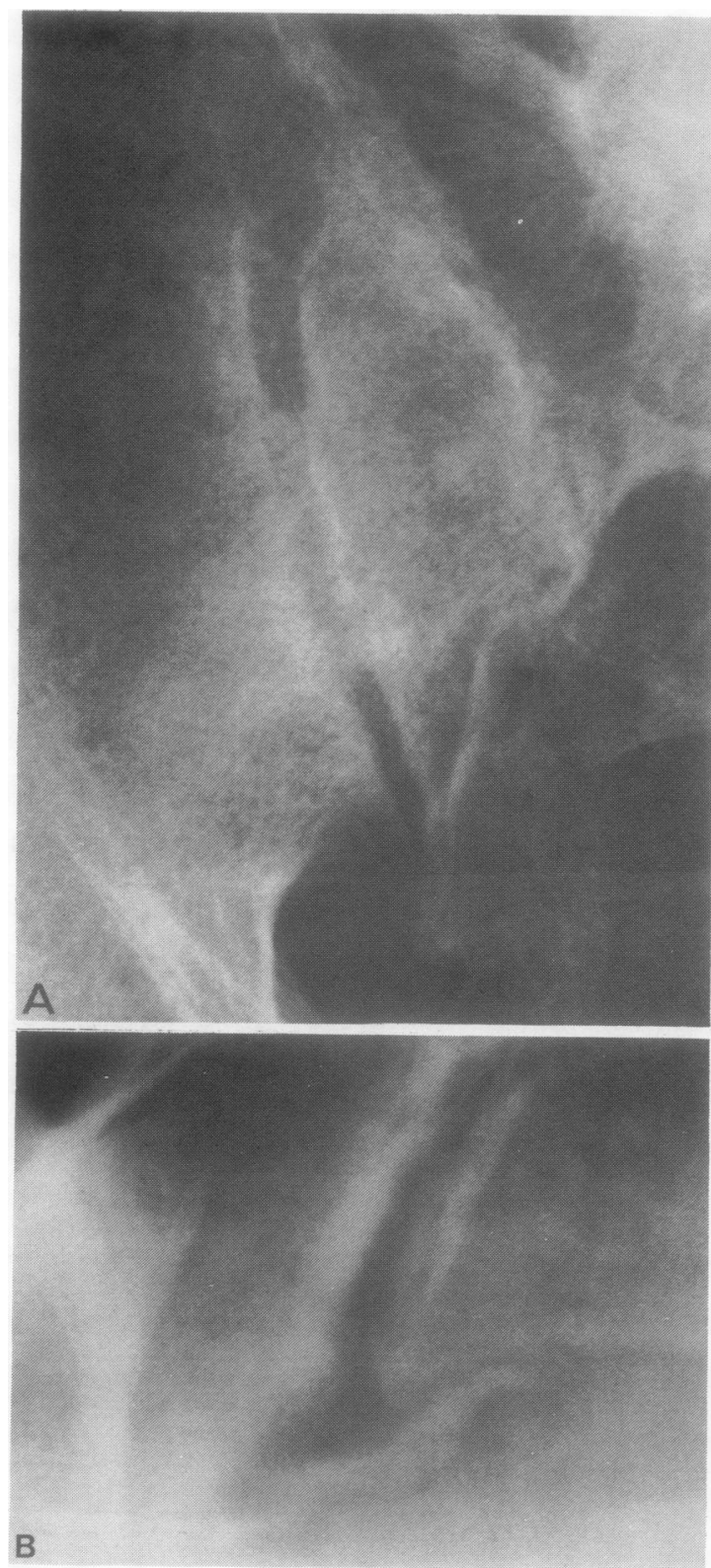

Fig. 5 Right sacroiliac joint of a 71-year-old VAH male. A. Anteroposterior view with blurring of the middle part of the joint. B. Craniocaudal axial view demonstrating capsular ossification, as a complete ventral bridge; notice clear space between sacrum and bridge.
Cranial and ventral capsular bony bridges occurred more often in the VAH group, but this was true only in men: 28 out of 32 , or $87 \cdot 5 \%$ had a cranial and/or complete or incomplete ventral bridge, compared
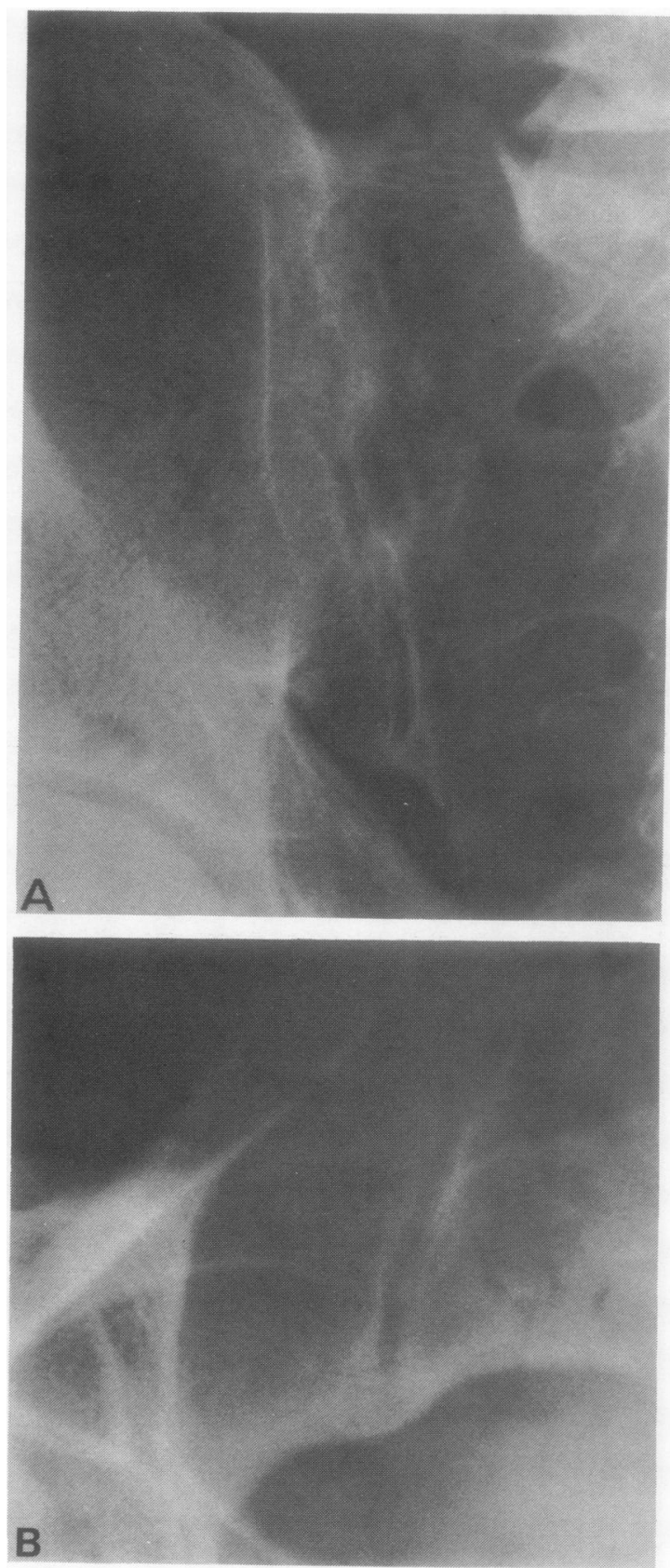

Fig. 6 Right sacroiliac of a VAH male with complete bridging cranially and caudally (A) as well as ventrally (B). 
with 4 out of 24 control men $(p<0 \cdot 0005)$. Caudal bridges were also more frequent in VAH men, but this difference did not reach statistical significance.

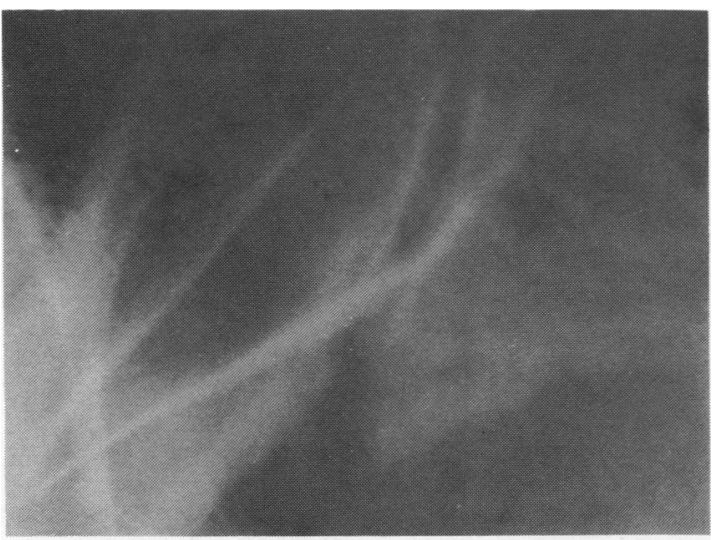

Fig. 7 Craniocaudal axial view of the right sacroiliac joint of a VAH female exhibiting incomplete bridge starting from the sacral side.

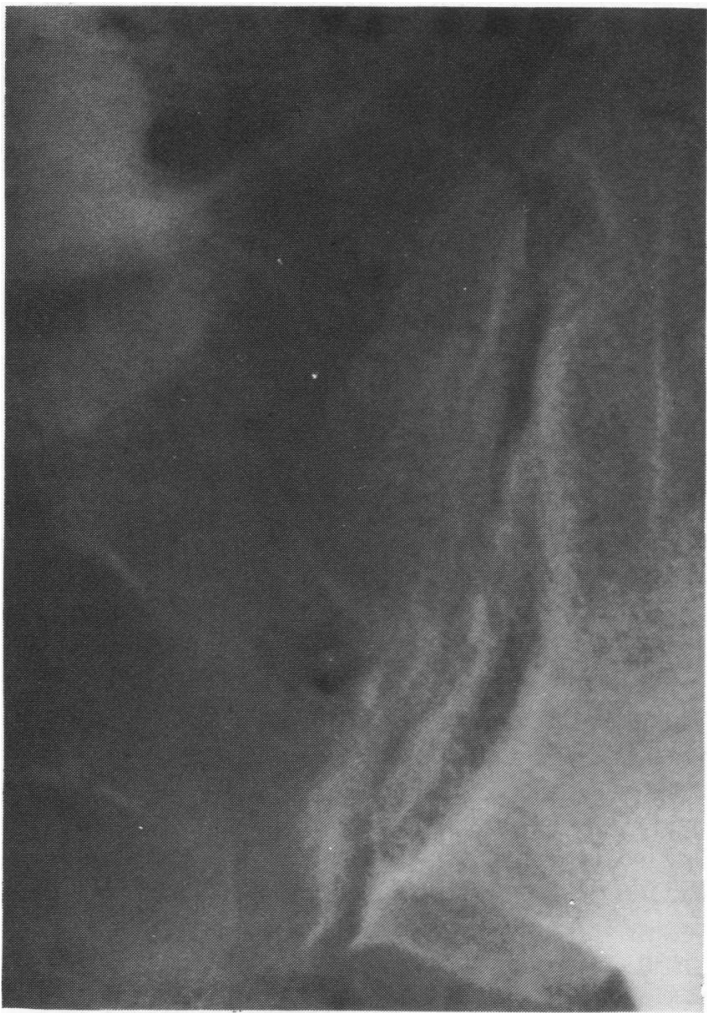

Fig. 8 78-year-old female; osteophyte at the inferior margin of the left sacroiliac joint and sclerosis of the ilium.
Extra-articular ankylosis of the SI joints was rare in women with VAH and nearly absent in control women (only one caudal ankylosis in 22 subjects).

When a capsular ossification occurred in control men, it was either cranial or ventral. In contrast, VAH patients often had a combined cranial and ventral extra-articular bony bridge, which meant that the

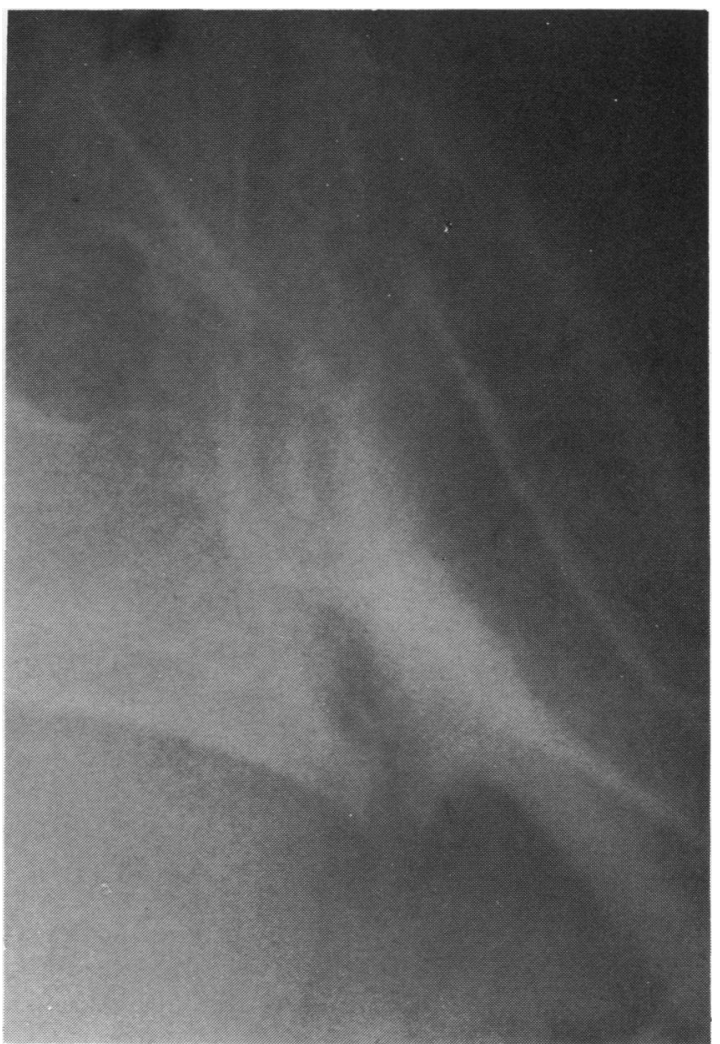

Fig. 9 42-year-old female; craniocaudal axial view of the left sacroiliac joint. The orientation of the osteophyte in the same plane as the articular surfaces will be noted.

Table 5 Number of male $V A H$ patients with cranioventral sacroiliac capsular ossification, according to age

\begin{tabular}{lcllll}
\hline Age & $\begin{array}{l}\text { No. of } \\
\text { patients }\end{array}$ & \multicolumn{3}{l}{ No. of patients with cranioventral capsular ossification } \\
\cline { 3 - 6 } & & Cranial & $\begin{array}{l}\text { Complete } \\
\text { ventral } \\
\text { bridge }\end{array}$ & $\begin{array}{l}\text { Incomplete } \\
\text { ventral } \\
\text { bridge }\end{array}$ & $\begin{array}{l}\text { All } \\
\text { cranioventral }\end{array}$ \\
\hline $31-40$ & 1 & 0 & 0 & 1 & 1 \\
$41-50$ & 3 & 1 & 0 & 1 & 2 \\
$51-60$ & 6 & 4 & 5 & 2 & 6 \\
$61-70$ & 13 & 8 & 7 & 4 & 11 \\
$71-80$ & 6 & 3 & 3 & 1 & 5 \\
$81-90$ & 3 & 2 & 2 & 1 & 3 \\
Total & 32 & 18 & 17 & 10 & 28 \\
\hline
\end{tabular}



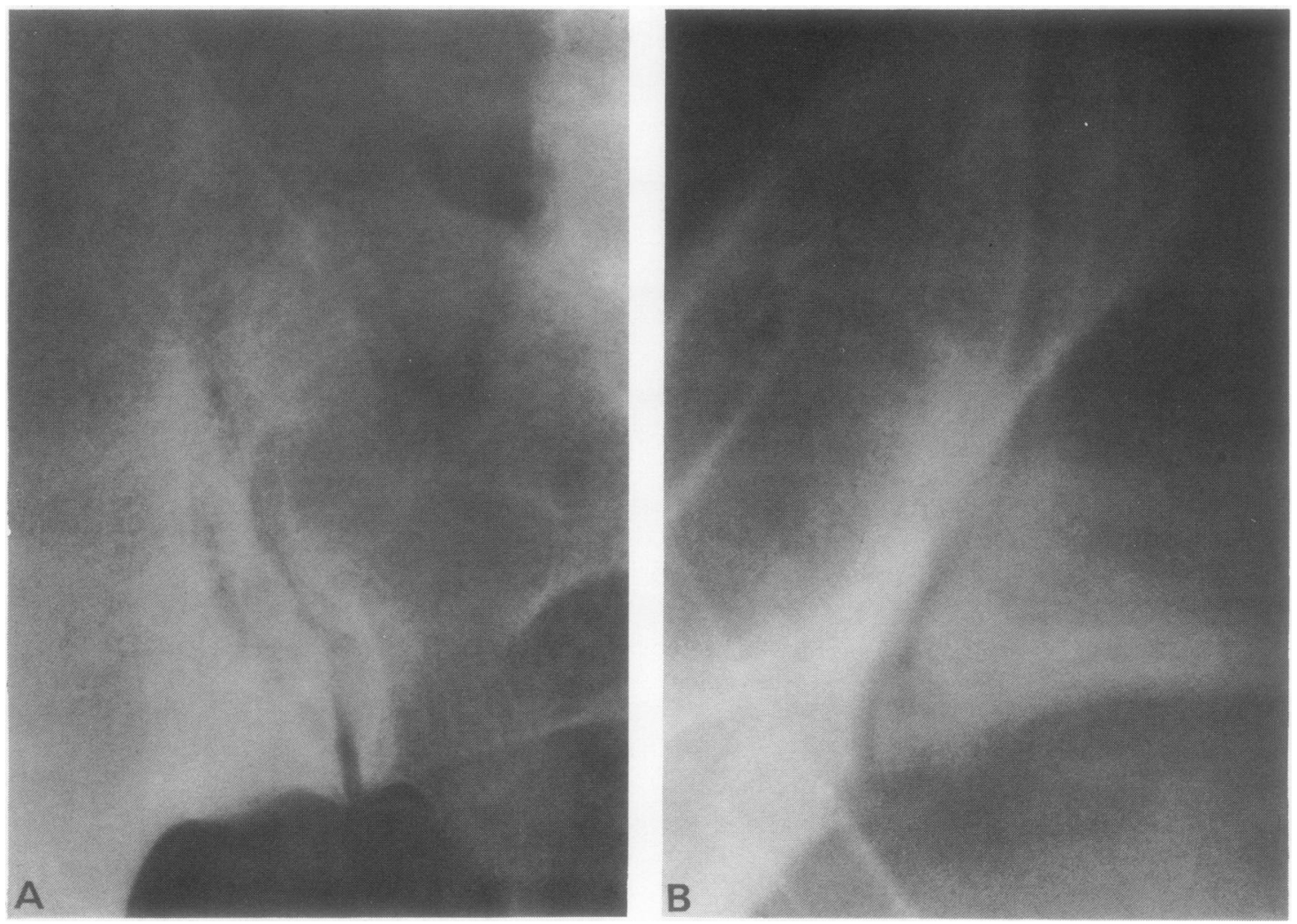

Fig. 10 Broad area ofsclerosisof the ilium in a 63-year-old female. A. Anteroposterior projection. B. Craniocaudal axial view.

process was more extensive. In 10 of them, however, the ankylosis was restricted to the ventral area of the joint, and was visible only on the craniocaudal axial view.

There was no statistically significant difference between VAH and control group as regards the prevalence of osteophytes and juxta-articular bone sclerosis.

Osteophytes were commoner in control women (11 out of 22) than control men (4 out of 24) $(\mathrm{p}<0.025)$.

As regards the influence of age, no significant difference was found in the incidence of osteophytes between the various age groups (Table 4). Table 5 displays the prevalence of cranioventral capsular ossification in VAH men according to age. The cranioventral bridges were frequent even in the younger patients, but complete ventral bridging was not observed before 50 years of age. A few incomplete ventral bridges were encountered after 70 years of age, indicating a late onset.

\section{Discussion}

Cranioventral capsular ossifications are not an aging phenomenon. They are seen in $87.5 \%$ of VAH men; they can start at any age and are seen even in the youngest VAH males.

Women seem to be protected against SI ankylosis. That pregnancy relaxes the SI ligaments is well known. So far as we know, the women in both groups are not exceptionally multiparous, nor are cranioventral bridges linked to a reduced childbirth rate. One might suggest that a stiff pelvis is a threat to species survival and that some fundamental mechanism would make the female SI junction less prone to ankylosis than in the male. Brooke ${ }^{3}$ has stated that in the female SI joint after puberty strength and solidity are sacrificed for increased mobility and that SI ankylosis in advanced age is confined strictly to the male sex.

The maintained mobility of SI joints in females probably accounts for the increased incidence of 
osteophytes, which has been observed both in VAH and in control subjects. One might argue that the low percentage of osteophytes in VAH men could be due to the frequent presence of complete bridges masking osteoarthrotic spurs or impeding their development. This argument does not hold for the comparison between male and female control subjects.

What interpretation should be given to the 4 cranioventral ossifications observed among the 24 control men $(16 \cdot 6 \%)$ ? Some might result from trauma or abnormal overload. Aging could provoke some SI capsular ossification, a tendency that would be strongly enhanced in VAH. A third explanation would be that those four 'control' subjects would in fact have incipient VAH. This would not be surprising in view of the fact that in the population from which our patients come most people suffering from generalised spinal complaints show some vertebral hyperostotic changes. It took 3 years to collect 46 adequate control patients. No doubt the collecting period would have been shorter if we had thought it ethical to $x$-ray asymptomatic persons.

Some authors call VAH a major form of spinal spondylosis, ${ }^{7}$ osteoarthritis, ${ }^{8}$ or osteophytosis, ${ }^{9}$ but Forestier and his coworkers ${ }^{1011}$ consider it to be a separate entity. Several facts are in favour of the latter theory. Spinal osteoarthritis affects mainly the cervical and lumbar segments, whereas VAH typically involves the dorsal area. In VAH intervertebral discs are usually not narrowed. According to Resnick and Niwayama ${ }^{12}$ the most conspicuous bridges are found across normal discs. The SI cranioventral bridges and osteophytes seem to be different changes. Osteophytes are orientated in the plane of the articular surfaces, whereas capsular ossifications are at a cross-angle. The capsular ossifications are not preceded by osteoarthrotic spurs, and they proceed without joint space narrowing or subchondral bone sclerosis.
We share Lagier and Baud's view ${ }^{13}$ of VAH being a diffuse enthesopathy. Van Linthoudt and François ${ }^{14}$ recently showed by microradiography and tetracycline labelling that the hallmark of VAH, the paravertebral bone casting, results from ossification of the ligamentous insertions into the vertebral body.

\section{References}

${ }^{1}$ Forestier J, Rotes-Querol J. Hyperostose ankylosante vertébrale sénile. Rev Rhum Mal Osteoartic 1950; 17: 525-34.

2 Dihlmann W, Freund U. Die Iliosakralveränderungen bei der nichtentzündlichen Wirbelsaülenversteifung (hyperostose ankylosante vertébrale sénile, spondylosis hyperostotica). Z Rheumnatol 1968; 27: 284-91.

${ }^{3}$ Brooke R. The sacroiliac joint. J Anat 1923/24; 58: 299-305.

4 Sashin D. A critical analysis of the anatomy and the pathologic changes of the sacroiliac joints. J Bone Joint Surg 1930; 12: 891-910.

${ }^{5}$ Putschar W. Entwicklung, Wachstum und Pathologie der Beckenverbindungen des Menschen, mit besonderer Berücksichtigung von Schwangerschaft, Geburt und irhen Folgen. Iena: Fischer, 1931.

- Dory M A, François R J. Craniocaudal axial view of the sacroiliac joint. $A J R$ 1978; 130: 1125-31.

7 Ott V R. Uber die spondylosis hyperostotica. Schweiz Med Wochenschr 1953; 83: 790-9.

${ }^{8}$ Biressi P C, Mussa L. Ricerche radiologiche e anatomopatologiche sull' artrosi disco-somatica a carattere iperostosante del rachide dorsale. Reumatismo 1957; 9: 1-37.

- Vignon G, Durant J, Pansu D, Bertrand J N, Truchot R. La spondylorhéostose ou hyperostose ankylosante sénile (à propos de 25 observations). Rev Rhum Mal Osteoartic 1961; 28: 428-35.

${ }^{10}$ Forestier J, Certonciny A, Deslous-Paoli P. Hyperostose rachidienne ankylosante. J Radiol Electrol Med Nucl 1956; 37: 835-8.

1 Forestier J, Lagier R. Ankylosing hyperostosis of the spine. Clin Orthop 1971; 74: 65-83.

12 Resnick D, Niwayama G. Radiographic and pathologic features of spinal involvement in diffuse idiopathic skeletal hyperostosis (DISH). Radiology 1976; 119: 559-68.

${ }^{13}$ Lagier R, Baud C A. Diffuse enthesopathic hyperostosis - anatomical and radiological study on a macerated skeleton. ROEFO 1978; 129: 588-97.

14 Van Linthoudt D, François R J. Hyperostose vertébrale ankylosante. Apport de la microradiographie et de la microscopie de fluorescence à l'étude du rachis dorsal. Rhumatologie 1981; 33: 89-98. 